\title{
Clausewitz, Realismo Estrutural e a Paz Democrática: Uma Abordagem Crítica*
}

Flávio Pedroso Mendes**

\section{Introdução}

O propósito deste artigo é a apreciação crítica do sistemático estudo da paz democrática realizado por Oneal e Russett (2001). Trata-se de uma inserção no campo de pesquisa comprometido com a correlação entre o tipo de regime político doméstico dos Estados e o nível de estabilidade no sistema internacional. Particularmente, teóricos da paz democrática acreditam - em geral partindo da simplificação dicotômica democracias/autocracias - que a natureza do regime político dos Estados tem influência direta sobre seu padrão de compor-

\footnotetext{
* Artigo recebido em 21 de dezembro de 2010 e aprovado para publicação em 25 de outubro de 2011. ** Doutorando em Relações Internacionais pela Universidade de São Paulo (USP) e professor de Relações Internacionais da Universidade Federal de Uberlândia (UFU). E-mail: flaviochopin@ gmail.com.
} 
tamento no ambiente internacional, com ênfase à propensão ao recurso às armas para a resolução de disputas políticas. ${ }^{1}$ Mais ainda, esses teóricos acreditam identificar um padrão geral para essa influência: Estados sob democracias representativas são mais pacíficos e tolerantes do que Estados sob regimes autoritários. Em Triangulating peace - democracy, interdependence and international organizations, Oneal e Russett inserem-se inequivocamente nesta tradição: "nossa hipótese é de que democracias raramente lutarão ou mesmo ameaçarão umas às outras, e possivelmente são mais pacíficas em geral" (ONEAL; RUSSETT, 2001, p. 91).

O estudo de Oneal e Russett é importante e representativo por uma série de razões. Em primeiro lugar, ele avança para além da variável "tipo de regime" e abrange os subprodutos liberais da tradição democrática nas relações internacionais: a interdependência econômica e a participação em instituições internacionais. Em segundo lugar, ele oferece uma construção teórica sistemática para explicar as correlações observadas na extensa base empírica analisada, preenchendo uma das principais lacunas apontadas, entre outros, por Gray (1999) e Waltz (2000). ${ }^{2}$

Por último, e talvez mais importante, o estudo tenta incorporar e controlar algumas variáveis identificadas com a principal abordagem rival: o realismo político. Como ficará claro adiante, Oneal e Russett julgam ser capazes de observar e controlar o efeito de variáveis "realistas", demonstrando, supõe-se, o impacto independente das variáveis liberais sobre a propensão ao conflito interestatal. Se esse exercício tiver sido de fato bem-sucedido, tem-se uma importante vitória para os teóricos da paz democrática.

Entretanto, Oneal e Russett falham em suas duas principais tentativas de contribuição. O princípio causal identificado para explicar o pacifismo intrínseco às democracias representativas não resiste ao entendimento, em toda a sua extensão, da noção da guerra como um instru- 
mento político, derivado da mais sólida investigação do fenômeno bélico: a teoria da guerra de Clausewitz. Incidentalmente, a crítica construída a esse respeito ultrapassa as páginas do estudo de Oneal e Russett e se estende a todo o empreendimento dos teóricos da paz democrática, na medida em que eles partem mais ou menos dos mesmos pressupostos. Oneal e Russett são incapazes, ainda, de identificar e controlar as variáveis "realistas" como pretendido. Tal incapacidade é patente quando se entende a lógica subjacente ao realismo estrutural, vertente do realismo político mais influente e com maior fôlego nas últimas três décadas, e se apuram adequadamente suas expectativas concretas quanto às dinâmicas da política internacional. $\mathrm{O}$ corolário dessa constatação é que os autores falham em se precaver contra manifestações epifenomenais, diminuindo dramaticamente a força de sua abordagem como ferramenta analítica alternativa e independente.

A próxima seção apresenta a discussão da paz democrática e a maneira como Oneal e Russett conduziram seu estudo. A segunda oferece um entendimento sumarizado da teoria da guerra de Clausewitz e de algumas de suas implicações. A terceira trata do realismo estrutural e apresenta sua lógica interna, da qual derivam suas principais expectativas sobre as dinâmicas políticas internacionais. A conclusão traz algumas considerações acerca das lições de Clausewitz e do realismo estrutural para o campo da paz democrática em geral e, em particular, para a contribuição de Oneal e Russett.

\section{A Paz Democrática}

Partindo de uma sumarizada leitura das relações internacionais desde a criação do moderno sistema de Estados no século XVII, Oneal e Russett (2001) acreditam ser capazes de identificar a recorrência de alguns círculos. Os círculos viciosos são atribuídos a alguns princípios causais identificados pelos autores do realismo político, princípios estes manifestados na caracterização do dilema da segurança e na 


\section{Flávio Pedroso Mendes}

consequente competição por segurança e poder (ONEAL; RUSSETT, 2001, p. 22-33). Entretanto, os autores acreditam que alguns elementos podem gerar círculos virtuosos de paz e cooperação, como testemunhariam os Estados que construíram nas últimas décadas o que é hoje a União Europeia. Oneal e Russett vão buscar os elementos desse círculo virtuoso em uma tríade que teria sua fundamentação no filósofo moderno Immanuel Kant: democracia representativa, interdependência econômica e instituições internacionais (ONEAL; RUSSETT, 2001, p. 35-42). Tais elementos seriam intrinsecamente capazes de gerar Estados mais pacíficos e tolerantes. Mais ainda, os três elementos seriam capazes de reforçar-se mutuamente.

Instituições políticas democráticas são apresentadas como a semente para um ambiente internacional mais harmonioso. Além de suas próprias virtudes, um regime democrático e representativo geraria como subproduto liberal um maior incentivo à integração econômica e à participação em fóruns multilaterais, atributos capazes de contribuir ainda mais para a cooperação interestatal. A tese geral é assim formulada: "a democracia tem um grande impacto na redução de conflitos: democracias não lutam com outras democracias e são mais pacíficas em geral" (ONEAL; RUSSETT, 2001, p. 82). Trata-se, no vocabulário dos teóricos da paz democrática, de uma tese que abrange as versões monádica e diádica da teoria. De acordo com Chan (1984), pode-se abordar o tema da paz democrática com o objetivo de apurar se democracias são mais pacíficas entre si (tese diádica) - o que Chan julga ser amplamente corroborado -, ou se democracias são mais pacíficas em geral, tanto em comparação com outras democracias quanto com governos autoritários (tese monádica). Oneal e Russett apostam na versão mais exigente da teoria e acreditam no pacifismo geral das democracias.

A lógica causal do argumento é simples. Governos democráticos são mais sensíveis aos interesses e preferências da população do que governos autoritários, já que dependem dos votos populares para se 
manter no poder. Se guerras geram morte, destruição e privação socioeconômica, elas tendem a ser altamente impopulares, o que desincentiva governos democráticos a seguir esse curso de ação. Nas palavras dos autores: "as pessoas tipicamente desejam a paz não apenas pela ausência de mortes, mas pela oportunidade de viver vidas normais. A paz não é só comum; ela é desejável" (ONEAL; RUSSETT, 2001, p. 81-82). Desse modo, governantes democráticos autointeressados evitariam as guerras como forma de manter seu apoio popular. Cabe ressaltar que essa premissa de Oneal e Russett, de resto compartilhada pelo grosso da literatura no campo, de fato é mais compatível com a tese monádica do pacifismo geral das democracias. Afinal, se o elemento causal é a repulsa popular pelos efeitos e constrangimentos impostos por confrontações armadas, o regime político de um eventual oponente em quase nada importaria. ${ }^{3}$

Os subprodutos liberais - interdependência econômica e participação em instituições internacionais - gerariam também, segue o argumento, contribuições independentes para a paz. Uma maior interdependência econômica entre dois Estados supostamente faz com que eles tenham maiores incentivos para manter a paz entre eles, na medida em que o bem-estar de um depende em parte do bem-estar do outro (ONEAL; RUSSETT, 2001, p. 127-133). E instituições internacionais exerceriam sua influência positiva basicamente a partir dos seguintes mecanismos: elaboração de normas de conduta e de resolução de controvérsias, provimento de informação, reformulação dos interesses e preferências dos Estados, instrumentos de enforcement e de monitoramento etc. (ONEAL; RUSSETT, 2001, p. 159-167). ${ }^{4}$

A proposta de Oneal e Russett é testar empiricamente a hipótese do pacifismo geral das democracias e o efeito dos demais elementos da tríade kantiana. Os autores, entretanto, acreditam que algumas variáveis identificadas por teóricos realistas influenciam de fato a vida internacional e são capazes de provocar os trágicos círculos viciosos retratados pela história da política internacional. Ao contrário de ne- 
gar esses efeitos, os autores julgam ter de identificá-los, controlá-los e, assim, dar conta do impacto independente das variáveis liberais que lhes interessam. Com efeito, Oneal e Russett (2001, p. 90) atestam: "nós combinamos as perspectivas realista e liberal" e "o realismo apresenta a base contra a qual o efeito das influências liberais pode ser comparado". Os autores almejam efetivamente complementar a abordagem realista, agregando variáveis que teriam um impacto independente e discernível na propensão à ocorrência de guerras. Naturalmente, a condição de complementaridade - no lugar de uma simples manifestação epifenomenal - depende da capacidade dos autores de controlar a independência dos efeitos previstos pelas duas abordagens teóricas. As variáveis "realistas" propostas por Oneal e Russett são:

(i) Geografia: "quanto mais distantes dois Estados estiverem um do outro, menos provável será uma luta entre eles" (ONEAL; RUSSETT, 2001, p. 86). O ponto aqui é controlar a proximidade geográfica entre os Estados como variável interveniente sobre a propensão ao conflito entre eles;

(ii) Poder: "a probabilidade de que dois Estados lutarão é menor quando há uma balança de poder igual entre eles, ou quando um dos lados tem muito mais poder do que o outro?" (ONEAL; RUSSETT, 2001, p. 88). Aqui, o que interessa é controlar a correlação de poder em um determinado par de Estados, diante da hipótese de que uma eventual assimetria de força diminua a probabilidade de guerra por efeito da dissuasão; ${ }^{5}$

(iii) Alianças: "aliados geralmente não lutam ou ameaçam um ao outro com ação militar" (ONEAL; RUSSETT, 2001, p. 103). O controle aqui é feito pelo tipo de relacionamento entre dois Estados em um determinado momento, supondo poderem ser aliados ou não aliados - no caso dos primeiros, com uma propensão menor à guerra entre eles do que no segundo caso. ${ }^{6}$ 
Os autores se propõem a testar todo o conjunto de relações bilaterais (diádicas) entre os Estados, por ano, no período de 1885 a 1992. A variável "conflito" é buscada no banco de dados do programa Correlates of War e os autores se dizem interessados em "disputas militarizadas" em geral, mesmo as que estejam aquém de uma confrontação aberta. Trata-se de uma variável binária, que indica disputa ou não disputa. A variável "democracia” é gradativa e baseada em critérios gerais de abertura e de oposição, podendo ir de -10 (totalmente autoritário) a +10 (perfeitamente democrático). ${ }^{7}$ A variável "interdependência econômica" é medida pela razão entre o montante do intercâmbio comercial de um país (com seu par na díade) e o seu PIB. Por fim, a variável "instituição internacional” é medida, também em pares de países, a partir do número de organismos internacionais a que os dois Estados pertençam simultaneamente (ONEAL; RUSSETT, 2001, p. 91-104; p. 138-145; p. 169-171).

Para testar a probabilidade de que alguma mudança nessas variáveis - e também nas variáveis "realistas" - altere a probabilidade de conflito entre dois Estados, os autores partem de um "par típico" de Estados como parâmetro de base. O "par típico" é formado por Estados contíguos, não aliados, nenhum deles sendo uma grande potência e com valor 0 no espectro autoritário-democrático. A probabilidade de ocorrência de um conflito em um determinado ano entre um "par típico" foi verificada como sendo, segundo os autores, de 0.06 ou $6 \%$ (ONEAL; RUSSETT, 2001, p. 108).

O teste multivariado confirmou, para Oneal e Russett (2001, p. 108), que as variáveis "realistas" são capazes de influenciar a probabilidade de conflito entre dois países, e no sentido previsto pelas hipóteses apresentadas: se os Estados forem aliados no momento da observação, a probabilidade de conflito cai em 46\%, e se a razão de poder (variável que mede a correlação de força) aumentar em um desvio padrão, a probabilidade de conflito cai em $29 \%$. 
Mais importante para os autores, ao incremento no valor de cada uma das variáveis kantianas correspondeu, conforme os resultados apresentados, uma diminuição significativa da probabilidade de conflito entre os pares de Estados, controladas as variáveis "realistas". Para a variável que nos interessa diretamente - "tipo de regime" - Oneal e Russett (2001, p. 108) apresentaram o seguinte resultado: o aumento de um desvio padrão no espectro autoritário-democrático (-10/+10) correspondeu a um decréscimo de $42 \%$ na probabilidade de conflito; a diminuição de um desvio padrão no espectro aumentou as chances de conflito em 69\%; e a elevação ao valor máximo (+10) diminuiu a probabilidade de conflito em $54 \%$, ao passo que a estipulação do valor mínimo (-10) aumentou a probabilidade em $109 \% .{ }^{8}$ Como esperavam os autores, a atuação conjunta dos três elementos da tríade kantiana parece fornecer a maior expectativa de paz entre dois Estados quaisquer $-71 \%$ a menos de chance de conflito. Para os autores, apresenta-se a receita para um mundo mais próspero e mais pacífico para os Estados nacionais.

\section{Clausewitz e a Guerra como Instrumento Político}

Carl Von Clausewitz foi o primeiro a dar um tratamento verdadeiramente científico ao fenômeno da guerra, rompendo com a tradição de elaboração de manuais de conduta na guerra e de regras para a vitória. ${ }^{9}$ Clausewitz se propunha a entender a guerra em sua integralidade e complexidade, identificando seus elementos definidores e o relacionamento entre eles. Para tanto, o método utilizado por Clausewitz não foi estranho ao empreendimento científico em geral. $\mathrm{Na}$ descrição de Proença Jr. et al. (1998, p. 78):

Assim, transparece aquilo que é o método científico clausewitziano: definir um conceito; extrair dele todas as suas consequências lógicas; verificar se e como essas consequências lógicas são respaldadas pela realidade, tomando a 
realidade como critério de validade; incorporar as diferenças com a realidade à formulação teórica, agregando ao conceito puro todas as determinações que a realidade impõe.

Indo por partes, Clausewitz partiu de uma concepção abstrata de guerra, que captasse a sua essência. Para Clausewitz, essa essência é a luta, o embate físico entre duas partes, uma tentando submeter a outra e deixá-la incapaz de resistir. Nasceu um conceito aparentemente simples, mas em cujos desdobramentos reside a gênese da ciência do bélico: "a guerra é portanto um ato de força para compelir nosso oponente $^{10}$ a fazer a nossa vontade" (CLAUSEWITZ, 1993, p. 83). Os termos centrais do conceito clausewitziano de guerra são "ato de força", "compelir" e "nossa vontade" (PROENÇA JR.; DINIZ, 2006). $\mathrm{O}$ "ato de força" delimita o fenômeno em termos de seus meios - a força -, separando-o de outras manifestações em que meios exclusivamente não violentos sejam empregados. "Compelir" indica a necessidade de dobrar o oponente, obrigá-lo a algo a que ele naturalmente se opõe. E "nossa vontade" diz respeito ao objeto de toda a ação, o motivo que levou ao emprego do meio força e que causou a oposição do outro, que por isso mesmo se tornou um oponente.

O passo seguinte da investigação empreendida por Clausewitz foi derivar os desdobramentos lógicos do seu conceito de guerra. O resultado foi o que Clausewitz denominou de "três interações", que logicamente deveriam conduzir ao exercício irrestrito e extremo da violência na guerra. A primeira delas advém da caracterização da guerra como um “ato de força”. Para Clausewitz, não há limite lógico ao emprego da força e aos esforços para destruir o oponente. Diante disso, se um lado moderar deliberadamente seus esforços e o outro não, o primeiro se veria em desvantagem e correria o risco de sofrer uma derrota. Uma vez que ambos os lados saibam disso, a tendência é a da aplicação mútua do máximo de força disponível (CLAUSEWITZ, 1993, p. 83-85). 
A segunda interação nasce do imperativo mais natural que, para Clausewitz, surge de uma confrontação armada: desarmar o oponente e deixá-lo incapaz de seguir lutando. Na medida em que esse imperativo vale para os dois lados, colocar-se-ia a cada um a necessidade de desarmar o outro antes que ele próprio seja desarmado. Portanto, mais uma vez a tendência ao emprego extremo e irrestrito da força se manifestaria (CLAUSEWITZ, 1993, p. 85-86).

A terceira e última interação advém da necessidade de superar o poder de resistência do oponente, mediante um cálculo que considere os meios à sua disposição e a força de sua vontade. O outro lado procederá da mesma forma, engendrando um relacionamento competitivo que só poderia resultar no máximo dispêndio de todos os meios à disposição (CLAUSEWITZ, 1993, p. 86).

Das "três interações", desdobradas logicamente do conceito de guerra como um ato de força para obrigar o outro a fazer a nossa vontade, deriva o tipo de guerra conceitual, ou "guerra no papel", que Clausewitz caracteriza como uma guerra absoluta. A guerra seria absoluta porque se daria em um gigantesco espasmo de violência, um choque único de todo o montante de energia e recursos mobilizáveis pelos contendores. Não poderia ser diferente se somente as dinâmicas e interações previstas pelo conceito estivessem em jogo.

A relação estreita de Clausewitz com a ciência tem origem no terceiro passo de sua construção, quando o autor vira os olhos para a realidade e se propõe a analisar a história das guerras. A honestidade com que Clausewitz empreendeu seu estudo não lhe permitia deixar escapar uma conclusão muito clara: as guerras reais diferiam e muito da forma absoluta prevista conceitualmente. Três diferenças marcantes se impunham: (i) a guerra na realidade nunca é um ato isolado, à parte do contexto político que envolve os dois lados em conflito; (ii) a guerra na realidade não consiste em um único choque instantâneo, em que toda a parada é decidida; e (iii) os resultados das guerras reais 
nunca são finais (CLAUSEWITZ, 1993, p. 87-89). Diante disso, Clausewitz tinha duas saídas. A primeira era fiar-se na superioridade lógica da guerra conceitual ou absoluta, relegando como aberrações ou imperfeições as guerras que eram conduzidas na prática. A segunda, assumida por Clausewitz e em conformidade com os preceitos científicos, era empreender uma profunda análise dos elementos responsáveis pela discrepância e incorporá-los teoricamente.

Em síntese, a anomalia essencial que se impunha a Clausewitz era a existência de pausas na condução das guerras. De fato, Clausewitz constatou, curiosamente - porque frontalmente contrário às expectativas da forma conceitual de guerra -, que as pausas são a regra, não a exceção, no desenrolar das guerras reais. O desafio lógico das pausas na guerra é que, à primeira vista, os interesses dos contendores nunca deveriam coincidir, seja em momentos de ação ou de inação. Em outras palavras, quando a um lado conviesse esperar por uma ocasião mais favorável para um enfrentamento, ao outro naturalmente conviria tomar a iniciativa e evitar que as condições mais favoráveis se produzissem para o seu oponente. O resultado deveria ser uma sequência ininterrupta de enfrentamentos até a decisão final, aproximando a guerra de sua manifestação absoluta.

A explicação definitiva de Clausewitz para a ocorrência de pausas na guerra pertence ao estágio mais maduro e avançado do seu pensamento. ${ }^{11}$ Devem-se considerar, a esse respeito, duas conclusões essenciais: (i) não há uma polaridade verdadeira entre o ataque e a defesa, sendo antes duas formas qualitativamente distintas de guerra; e (ii) a defesa é intrinsecamente mais forte do que o ataque (CLAUSEWITZ, 1993, p. 94-95).

A polaridade existente entre $\mathrm{o}$ ataque - o lado que toma a iniciativa e deseja alterar o status quo - e a defesa - o lado cujo propósito é resistir à vontade do atacante e manter o status quo - se dá apenas na dimensão política e no resultado buscado na guerra. $\mathrm{O}$ atacante possui 
o propósito político positivo e busca alterar a situação, ao passo que o defensor carrega o propósito negativo e está comprometido com a manutenção do estado vigente de coisas. A polaridade aí é evidente. Da mesma forma, cada lado almeja atingir seu propósito por meio de uma vitória na guerra, que implica necessariamente uma derrota para o seu opositor. Aqui também a noção de polaridade se apresenta sem dificuldades.

Entretanto, Clausewitz chegou à conclusão de que não há polaridade no relacionamento entre ataque e defesa, que constituem formas qualitativamente distintas de condução da guerra. A distinção nasce da situação específica em que está colocado o defensor, simplesmente por ser o defensor, e que Proença Jr. e Diniz (2006, p. 14-15) resumem como sendo as vantagens da espera e da posição. A vantagem da espera deriva do propósito negativo do defensor, para quem o sucesso é garantido simplesmente se a situação permanecer do jeito que está. Cabe ao atacante agir e mudar as coisas para que seu propósito positivo seja atingido, caso contrário o defensor prevalece.

A vantagem da posição se refere ao fato de que a situação do defensor lhe permite utilizar alguns recursos de força negados ao atacante, a saber, os recursos imóveis: terreno, barreiras naturais, fortificações etc. Em suma, enquanto o atacante deve contar exclusivamente com suas forças móveis, deslocadas para enfrentar o defensor, o defensor pode utilizar uma série de recursos imóveis de seu território que potencializam sua força (PROENÇA JR.; DINIZ, 2006, p. 14-15). De imediato, isso significa que uma guerra travada nos moldes absolutos, como preveria o conceito de guerra, apresentaria uma desvantagem para o defensor, que não poderia empregar instantaneamente todos os recursos à sua disposição. Com isso, é natural que o defensor não queira buscar uma decisão por meio de um único e gigantesco embate, mas que busque utilizar seus recursos de forma sequenciada, valendo-se da vantagem inerente à sua posição. 
A segunda conclusão, correlata à primeira, é a de que a defesa é a forma intrinsecamente mais forte de guerra. Nas palavras de Clausewitz (1993, p. 95): “estou convencido de que a superioridade da defesa (se corretamente compreendida) é muito grande, bem maior do que parece à primeira vista". A razão para isso é que as próprias dinâmicas impostas para o ataque e para a defesa produzem o gradual enfraquecimento do primeiro e o progressivo fortalecimento da segunda. Os fatores que geram o enfraquecimento gradual do ataque são apresentados por Clausewitz em alguns capítulos do livro intitulado $\mathbf{O}$ ataque $^{12}$ (VII-4, VII-5 e VII-22) e são sintetizados por Diniz (2002, p. 112) da seguinte forma:

Os enfrentamentos travados com as vantagens da defesa produzirão perdas ao atacante. Além disso, na medida em que o ataque avança, ele vai adentrando terreno hostil - o que implica que, para poder explorar os recursos da área ocupada, ele terá que destacar forças para permiti-lo, forças que serão subtraídas aos enfrentamentos com o defensor que se seguirão; vai estendendo suas linhas de comunicação, expondo-as ao contra-ataque inimigo - e portanto tem que destacar forças para protegê-la, forças essas que serão também subtraídas dos futuros embates; vai se distanciando das fontes de reforços - dificultando a chegada de novas forças, que poderiam recompor suas forças para os enfrentamentos posteriores.

Ou seja, por deter o propósito positivo e ser obrigado a agir e buscar uma decisão, o ataque se expõe a um processo de exaustão progressiva de sua força. A defesa, de sua parte, atravessa um processo contrário. Ao recuar, tentando impor algumas perdas ao atacante em enfrentamentos favoráveis, o defensor se aproxima de sua fonte de suprimentos e reforços; encurta suas linhas de comunicação; encontra uma população solidária, que pode vir até a participar da luta como 
milícia; ganha em vontade e disposição, à medida que vê seu território sendo ocupado pelo atacante; e seus revezes tendem a lhe render aliados em função da lógica da balança de poder (CLAUSEWITZ, 1993, p. 445-450).

A despolarização do relacionamento entre ataque e defesa e a superioridade intrínseca da defesa explicam, sem contradição, a existência de pausas na condução de guerras: um lado, ou ambos, dada a dimensão momentânea de suas forças, podem ser fortes o suficiente para se defender, porém fracos demais para atacar. De acordo com Clausewitz (1993, p. 94, ênfases no original), "temos de perguntar se a vantagem de adiar uma decisão é tão grande para um lado quanto a vantagem da defesa é para o outro".

Retomando o que se mencionou por alto anteriormente, o terceiro elemento central da definição de guerra - "nossa vontade" - revela o seu caráter instrumental. A guerra é um meio, não um fim em si mesma, e seu fim é a concretização da nossa vontade, à qual se opõe a vontade do oponente, que precisa ser dobrada. A guerra nasce, portanto, de um conflito de vontades entre dois lados. A essa interação entre os objetivos de dois lados, ou à situação em que as vontades de um lado se esbarram nas vontades de outro, é que se pode entender amplamente como política. Clausewitz (1993, p. 99) propõe, assim, uma definição complementar e mais precisa de guerra: "a guerra é meramente a continuação da política por outros meios”.

Os relacionamentos políticos não são, entretanto, sempre violentos, como mesmo uma olhadela para a história poderia demonstrar. A guerra é, portanto, apenas uma das manifestações que as disputas políticas podem tomar, distinta das demais pelo acréscimo de seu instrumento próprio e definidor - a força. Desse modo, mesmo que a guerra seja apenas um dos meios à disposição da política, a política é sempre a motivação que está por trás de toda e qualquer guerra. Para Clausewitz (1993, p. 98), “quando comunidades inteiras vão à guerra 
- povos inteiros, e especialmente povos civilizados - a razão sempre reside em alguma situação política, e a ocasião é sempre devida a algum objeto político".

Considere-se agora mais uma tendência prevista pelo conceito de guerra que é afastada pelas imposições da interação entre ataque e defesa. Como se viu, a guerra absoluta, desdobrada logicamente do conceito de guerra, consistiria em um choque instantâneo de toda a força mobilizada pelos dois lados. Isso teria ainda uma consequência importante: a tendência ao deslocamento do propósito político pelo propósito de guerra. A guerra absoluta ou conceitual continuaria sendo um fenômeno político, motivado por uma disputa política, mas durante a sua execução a política sairia de cena e a guerra assumiria uma lógica própria. Independentemente da natureza do objetivo político da guerra, da sua importância e do seu valor, tudo o que importaria é prevalecer no gigantesco e imoderado espasmo de violência que teria lugar. Em outras palavras, a guerra, após ser acionada pela política, assumiria totalmente o controle e só o devolveria quando o resultado já tivesse sido produzido.

Ora, se as guerras reais deixam de ser absolutas, por conta do relacionamento entre ataque e defesa, e passam a ser constituídas por uma série de eventos temporalmente espaçados, o deslocamento da política pelo propósito de guerra não mais precisa acontecer. Isso significa que a política pode voltar à cena após o início das hostilidades e reavaliar suas considerações com base nos desdobramentos observados. A política, em conclusão, não só determina o recurso à guerra, mas permeia o fenômeno em toda a sua extensão: "vemos, portanto, que a guerra não é meramente um ato político, mas um verdadeiro instrumento político, uma continuação do intercurso político, realizado com outros meios" (CLAUSEWITZ, 1993, p. 99). O retorno da política à guerra, forçado pela natureza da interação entre ataque e defesa, é a chave para o entendimento das formas que as guerras podem assumir na realidade - limitada e ilimitada - e para a sua incorpora- 
ção como formas teoricamente legítimas de guerra. Clausewitz demonstra, assim, como corolário de uma constatação verdadeiramente científica, que a guerra é um fenômeno integralmente político, com desdobramentos integralmente subordinados às dinâmicas políticas.

\section{A Lógica do Realismo Estrutural}

Na obra que inaugura o realismo estrutural ${ }^{13}$ ou neorrealismo, Waltz (1979) defende a tese de que a expressiva recorrência dos principais fenômenos internacionais, a despeito da enorme diversidade dos atributos internos dos Estados (e unidades políticas anteriores ao Estado moderno) e de suas transformações socioeconômicas e políticas através dos tempos, indica a influência de fatores estruturais que transcendem o nível estatal. Em outras palavras, uma efetiva teoria das relações internacionais não pode prescindir de um elemento estrutural ou sistêmico. ${ }^{14}$

Da conclusão anterior surgia a necessidade de identificar constrangimentos advindos da estrutura do sistema e de diferenciá-los de causas no nível das unidades. De acordo com Waltz (1979), três elementos dão forma e caracterizam uma estrutura política, internacional ou doméstica: (i) seu princípio ordenador, ou seja, como as partes estão dispostas umas em relação às outras; (ii) a especificação de papéis e a diferenciação de funções entre as unidades; ${ }^{15}$ e (iii) a distribuição de capacidades no interior do sistema. Uma estrutura é formada pela combinação desses três elementos e uma mudança estrutural é concebida somente mediante alteração em pelo menos um deles. Aplicando essa lógica de construção estrutural ao sistema internacional, tem-se:

- A estrutura internacional é anárquica: ao contrário de um regime hierárquico, comumente encontrado no âmbito doméstico dos Estados, no qual vigora um claro relacionamento de supe- 
rioridade e subordinação entre as unidades e agências que compõem o sistema, no sistema internacional há uma necessária descentralização e ausência de vínculos de comando e obediência;

- Não há especificação de papéis e diferenciação entre as unidades. O fato é que a própria condição anárquica do sistema induz à semelhança de papéis e de funções. Em outras palavras, os Estados no sistema internacional são funcionalmente semelhantes e essa condição não se altera de uma estrutura internacional para outra, contanto que seu princípio ordenador continue sendo a anarquia;

- A distribuição de capacidades no interior da estrutura internacional informa o número de polos no sistema, vale dizer, o número de grandes potências que coexistem internacionalmente. Enquanto as capacidades são, sem dúvida, um atributo das unidades - portanto reducionista -, para Waltz a distribuição das capacidades é um fator estrutural que independe das unidades isoladamente.

Para explicar quais são os efeitos estruturais sobre o comportamento estatal, o neorrealismo parte do pressuposto de que o principal interesse dos Estados é garantir a sua própria sobrevivência, entendida como a manutenção de sua integridade territorial e de sua autonomia política. Esta situação, associada à condição anárquica do sistema internacional, dá à luz o incentivo estrutural mais elementar: os Estados têm de prover a sua própria segurança, na medida em que ninguém pode seguramente ${ }^{16}$ interceder por eles na eventualidade de ser posta em xeque a sua existência. Em outras palavras, Estados no sistema internacional se encontram em uma situação eminentemente de autoajuda (self-help). ${ }^{17}$ Os Estados são também incentivados a prestar atenção especial em como o poder se encontra distribuído entre eles, ou seja, a observar com cuidado a balança de poder no sistema. Estados possuem, assim, uma natureza eminentemente posicio- 
nal: importa-lhes como se encontram posicionados em relação aos demais, ou quão fortes eles são relativamente, pois só assim podem ser apuradas as suas condições de resistir a um eventual atentado à sua sobrevivência.

Diante do fortalecimento de um ou mais Estados, os demais têm sua segurança decrescida e a tendência é que os últimos se esforcem para restaurar o equilíbrio de poder: (i) aumentando internamente suas capacidades; (ii) formando alianças com os que também tiveram sua posição na balança de poder deteriorada; ou pelas duas formas. Ambos os mecanismos caracterizam esforços de balanceamento: o primeiro, de balanceamento interno; o segundo, de balanceamento externo (WALTZ, 1979). A insegurança e a incerteza são colocadas no centro das relações internacionais.

Mas se o pressuposto é de que os Estados buscam meramente garantir as suas possibilidades de sobrevivência, o fato de temerem tanto uns aos outros é algo contraintuitivo que deve ser explicado. Sua plausibilidade lógica reside na caracterização de uma dinâmica que se convencionou chamar dilema da segurança, assim sistematizada por Herz (1950):

Onde quer que tal sociedade anárquica tenha existido - e ela existiu em algum nível na maioria dos períodos da história conhecida - surgiu o que pode ser chamado de "dilema da segurança” de homens, grupos ou seus líderes. Grupos ou indivíduos vivendo em tal constelação devem estar, e geralmente estão, preocupados com sua segurança quanto a ser atacado, subjugado, dominado ou aniquilado por outros grupos ou indivíduos. Esforçando-se por obter segurança quanto a tais ataques, eles são movidos a adquirir mais e mais poder de modo a escapar ao impacto do poder alheio. Isto, por sua vez, torna os demais mais inseguros e os obriga a prepararem-se para o pior. Como ninguém po- 
de jamais sentir-se inteiramente seguro em tal mundo de unidades em competição, segue-se uma competição por poder, e o círculo vicioso de acumulação de segurança e de poder está instalado (HERZ, 1950, p. 157 apud DINIZ, 2002, p. 13).

O dilema da segurança retrata, portanto, a trágica situação em que Estados preocupados com sua própria sobrevivência buscam constantemente adquirir meios para garanti-la, incrementando suas capacidades; isso, no entanto, aumenta a insegurança dos outros, os quais, temerosos de que os incrementos adicionais dos demais sejam utilizados ofensivamente, tratam de aumentar suas próprias capacidades para fazer frente à ameaça potencial. Instaura-se um círculo vicioso, uma espiral de incerteza, que acaba por aumentar a insegurança e a desconfiança gerais. Na base lógica do dilema da segurança reside uma realidade tática e estratégica relacionada à ambiguidade dos meios de força, ${ }^{18}$ ou seja, ao fato de que as mesmas capacidades militares podem ser usadas tanto para atacar quanto para defender. $\mathrm{O}$ dilema da segurança é, com efeito, a base lógica do neorrealismo e reflete os dois processos pelos quais, para Waltz (1979), a estrutura do sistema internacional exerce indiretamente os seus efeitos: competição e socialização.

Em função da inocuidade do segundo elemento de uma estrutura política (distribuição de papéis e funções), estruturas internacionais só podem ser redesenhadas a partir de alterações em seu princípio ordenador ou na distribuição de capacidades entre os Estados. Enquanto o ambiente internacional permanecer desprovido de uma agência central capaz de controlar efetivamente o comportamento dos Estados (i.e., enquanto a anarquia subsistir como princípio ordenador), entretanto, mudanças estruturais terão lugar unicamente na ocorrência de alterações na distribuição de capacidade entre os Estados.

De acordo com Waltz, o sistema internacional admite duas formas estruturais: multipolar, composta por três ou mais grandes potências; 
e bipolar, formada por apenas duas grandes potências. Uma efetiva abordagem estrutural deve demonstrar quais são os diferentes efeitos sistêmicos gerados por estruturas distintas. Em linhas gerais, a lógica do realismo estrutural prevê que sistemas multipolares sejam mais instáveis do que sistemas bipolares, no sentido de serem mais propensos a mudanças mais dramáticas na configuração de poder. Isso equivale a identificar em sistemas multipolares uma maior propensão à ocorrência de guerras e à formação de alianças menos sólidas e duradouras. Mearsheimer (1990), nas linhas de Waltz, elabora essa expectativa com base em três pontos:

- Sistemas multipolares tendem a apresentar maiores oportunidades para a eclosão de guerras do que sistemas bipolares; ${ }^{19}$

- Desequilíbrios de poder são mais comuns em sistemas multipolares; ${ }^{20}$

- Sistemas multipolares abrem mais espaço para erros de cálculo do que sistemas bipolares. ${ }^{21}$

A discussão feita nesta seção apresentou a base lógica do realismo estrutural para explicar por que os Estados competem por poder e segurança no ambiente internacional, e como configurações internacionais distintas produzem constrangimentos distintos sobre o comportamento dos Estados e dão origem a expectativas igualmente distintas quanto à estabilidade do sistema. A conclusão a seguir traz algumas implicações da teoria da guerra de Clausewitz e do realismo estrutural para o estudo da paz democrática.

\section{Considerações Finais: Clausewitz, o Realismo Estrutural e a Paz Democrática}

A maneira como o princípio causal é construído por Oneal e Russett, para explicar por que é razoável esperar que democracias sejam in- 
trinsecamente mais pacíficas, sugere que, no fenômeno bélico, a escolha com que atores políticos se defrontam é simplesmente entre a guerra e a paz - entre morte e vida, entre turbulência e tranquilidade, entre privação e prosperidade etc. Sendo esse o caso, não seria preciso muito esforço para justificar por que a escolha de uma dada sociedade, supondo a sua capacidade de escolher, seria sempre pela recusa da guerra e em favor da paz. Mas o que Clausewitz demonstra, a partir de uma sólida construção teórica, é que a escolha de fato é sempre entre duas situações políticas - ou, se se quiser, entre dois tipos de paz-, uma atual e a outra possível apenas pelo recurso ao instrumento mais drástico do arsenal político: a guerra. Como descreve uma feliz passagem de Proença Jr e Diniz:

Uma das consequências mais desagradáveis da
consideração dos fenômenos táticos, estratégi-
cos e políticos e da interação entre ataque e de-
fesa nessas três dimensões é o reentendimento
da ideia de paz que daí decorre. De fato, qual-
quer situação concreta de paz - qualquer situa-
ção em que a interação política se dá sem o re-
curso à força - é sempre uma paz determinada:
uma paz que beneficia mais a um lado que a ou-
tro (PROENÇA JR.; DINIZ, 2006, p. 35).

É esse o entendimento adequado se se considera, em toda a sua extensão, a noção de guerra não apenas como um ato político, mas como um verdadeiro instrumento político. Esperar, portanto, que a escolha popular seja sempre pela recusa da guerra é presumir imediatamente que não haja situações políticas - status quo estabelecidos - indesejáveis o suficiente para justificar o esforço que a guerra demanda de uma sociedade. A pergunta inescapável quando se vislumbra essa situação, em qualquer momento, é, como lembram mais uma vez Proença Jr. e Diniz (2006, p. 35): "há coisas pelas quais vale a pena lutar?" Responder com uma negativa a essa pergunta, como o fazem indiretamente os teóricos da paz democrática, não só ignora os milênios de história humana, mas reflete uma açodada tentativa de resol- 
ver uma questão sem a ponderação adequada de toda a sua complexidade e profundidade. Para dar apenas um exemplo, o status quo político no norte da América na segunda metade do século XVIII justificava ou não a insurreição de um povo e uma sangrenta luta pela independência? Seria interessante ouvir de teóricos estadunidenses da paz democrática se uma América do Norte subserviente aos interesses ingleses no presente século XXI seria moral ou eticamente superior a toda a truculência que antecedeu o ano de 1776.

O entendimento adequado da teoria clausewitziana permite combater outra premissa equivocada subjacente ao princípio causal proposto pelos teóricos da paz democrática: a de que o elemento popular só entra nas considerações bélicas sob o manto da democracia participativa. Pode-se derivar da tese da paz democrática, da maneira proposta por Oneal e Russett, a noção de que o regime político democrático é o responsável pela incorporação do povo às considerações de guerra e de paz, e de que isso tem o potencial de alterar o status da guerra como instrumento viável ou desejável da política. Contudo, uma parte fundamental da construção teórica clausewitziana, não tratada na seção sobre Clausewitz deste artigo, incorpora teoricamente o povo como um dos três elementos centrais da guerra, como fenômeno, em qualquer lugar ou momento histórico. É impossível superestimar a importância da seguinte passagem de Clausewitz:

\begin{abstract}
A guerra é um verdadeiro camaleão, que adapta suas características ligeiramente a cada caso particular. Enquanto fenômeno integral, suas tendências dominantes sempre fazem da guerra uma trindade esquisita $-{ }^{22}$ composta de violência primordial, ódio e inimizade, que podem ser tratadas como uma força natural, cega; do jogo do acaso e de probabilidades, onde o espírito criativo pode enveredar livremente; e de seu elemento de subordinação, de instrumento político, que a faz subordinada apenas à razão.
\end{abstract}


O primeiro destes três aspectos diz respeito principalmente ao povo; o segundo ao comandante e à sua força; o terceiro ao governo. As paixões que devem ser inflamadas na guerra já devem estar presentes no povo; o alcance que a coragem e o talento terão no campo das probabilidades e do acaso depende do caráter particular do comandante e do de sua força; mas os objetivos políticos são província exclusiva do governo.

$[\ldots]$

Nossa tarefa é, portanto, desenvolver uma teoria que dê conta [da influência] destas três tendências, como um pêndulo suspenso entre três magnetos (CLAUSEWITZ, 1993, p. 101). ${ }^{23}$

Com a incorporação teórica do povo como um dos três elementos que compõem o fenômeno guerra, Clausewitz dissipa o corolário da abordagem da paz democrática de que a instituição moderna da democracia representativa apresentaria um novo estágio em que o caráter ou a vontade popular entrariam em cena para modificar as questões de guerra e de paz. Toda e qualquer guerra é movida em parte pela força natural, "composta de violência primordial, ódio e inimizade", centrada na população de uma polity; assim como "as paixões que devem ser inflamadas na guerra" sempre estiveram presentes no povo. A questão é: há algo intrínseco às sociedades atuais para esperar que essa força seja estéril ou que se manifeste sempre na direção esperada pela paz democrática? Não parece haver razões para acreditar neste tipo de transformação - não que os teóricos da paz democrática ofereçam uma.

Passando ao caráter mais metodológico da investigação de Oneal e Russett, emerge claramente da seção anterior que os autores não foram capazes de tratar e controlar as variáveis "realistas" como mandaria uma boa leitura do realismo estrutural. A variável "geografia" 
não é muito controversa e tem sua principal falha no modo de operacionalização (ver nota 7). Ademais, é bastante natural que o elemento de contiguidade territorial seja controlado na apuração da propensão ao conflito entre pares de Estados, e, ainda, a formulação clássica do realismo estrutural em Waltz (1979) não dá à geografia uma importância analítica digna de nota. ${ }^{24}$ Já as variáveis "poder" e "alianças", da maneira como foram tratadas por Oneal e Russett, estão em flagrante descompasso com as expectativas do realismo estrutural.

Como se viu, Oneal e Russett se propuseram a controlar a correlação de poder entre pares de países e se havia algum laço formal de alinhamento entre eles, de modo a verificar o impacto das variáveis "poder" e "alianças" sobre a propensão ao conflito. Contudo, como demonstrado, o realismo estrutural deriva suas expectativas concretas não de características específicas no relacionamento de díades estatais, mas antes da estrutura do sistema internacional. Portanto, o realismo estrutural pouco diz a partir da correlação de força entre dois Estados, mas busca seu nível de análise na distribuição de capacidades no interior do sistema. Da mesma forma, os padrões gerais de alinhamento - assim como seu impacto sobre a estabilidade internacional - são buscados nos constrangimentos sistêmicos ao comportamento dos Estados, e vão além da existência de vínculos formais de alianças entre pares observados. O período da Guerra Fria é útil para ilustrar as consequências da impropriedade cometida por Oneal e Russett.

Trata-se de um período particularmente relevante para a análise de Triangulating peace, primeiro porque compreende quase a metade de todo o horizonte analisado na pesquisa, ${ }^{25}$ e segundo porque foi durante os seus anos que surgiu e se desenvolveu o fenômeno que, para Oneal e Russett, corporifica e representa a grande promessa das teorias liberais para as relações internacionais: a União Europeia (ONEAL; RUSSETT, 2001, p. 24-29). Os autores estavam conscientes da marcante diferença estrutural entre a Guerra Fria e as décadas anteriores, em conformidade com o realismo estrutural, e julgavam 
essencial para sua abordagem ser capazes de dar conta dessa diferença: "por este critério [do realismo estrutural], o sistema internacional era multipolar por séculos antes de 1945, mas bipolar durante a Guerra Fria. Nós devemos considerar, portanto, se as relações internacionais foram diferentes nas duas eras" (ONEAL; RUSSETT, 2001, p. 92). Mas quão bem os autores foram capazes de dar conta das expectativas realistas para esse período?

Bem sumariamente, a estabilidade da Guerra Fria, uma situação de bipolaridade, é esperada pelo realismo estrutural não só em função da natureza do relacionamento entre as duas superpotências, mas do padrão geral de alinhamento entre as potências menores e as superpotências. Assim, espera-se, por exemplo, que o confronto entre um membro menor de uma aliança e outro membro menor da aliança rival, ou mesmo entre um membro menor e a superpotência rival, seja menos provável, pela capacidade disciplinadora das superpotências e por seu interesse desproporcional em manter o status quo, mesmo sem que haja uma aliança direta entre os dois Estados em questão. Também a correlação diádica de força só aparece como elemento analítico essencial entre as superpotências (nesse caso, essa correlação coincide com a própria distribuição de capacidades no interior do sistema, ou seja, com a própria polaridade). A correlação de força entre uma superpotência e um aliado menor da superpotência rival era menos importante do que o fato de que $o$ Estado menor era um aliado da superpotência rival, assim como a correlação de força entre membros menores da Organização do Tratado do Atlântico Norte (OTAN) e do Pacto de Varsóvia era menos importante do que os constrangimentos da bipolaridade sobre as duas alianças (ver notas 22, 23 e 24). Todos esses são efeitos importantíssimos derivados da lógica estrutural do neorrealismo, os quais o teste de Oneal e Russett é absolutamente incapaz de identificar e isolar.

Em suma, Oneal e Russett - assim como os teóricos da paz democrática em geral - baseiam-se em premissas falaciosas sobre as conside- 
rações de guerra e de paz na política internacional e sobre o lugar analítico do elemento "povo" em meio a essas considerações. Suas premissas não resistem ao tratamento teórico da guerra derivado da obra de Clausewitz. Oneal e Russett, em particular, falham ainda em sua contribuição potencialmente mais significativa ao campo da paz democrática: o controle de variáveis explicativas propostas no âmbito do realismo estrutural, de modo a corroborar a influência positiva e independente de variáveis liberais. A análise cuidadosa da lógica do realismo estrutural e de suas expectativas concretas quanto às dinâmicas da política internacional demonstra que não houve tal controle e, assim, os fenômenos caros aos teóricos liberais (como a integração europeia) continuam a ser manifestações epifenomenais subjacentes às dinâmicas previstas pelo realismo estrutural. Os teóricos da paz democrática têm um longo e árduo caminho pela frente, se de fato quiserem estabelecer sua abordagem como uma alternativa sólida e coerente para o estudo científico das relações internacionais.

\section{Notas}

1. Para uma apreciação deste campo de pesquisa, ver Chan (1984) e Bernoit (1996).

2. Waltz (2000, p. 7) afirma: "mas, se é verdade que democracias descansam confiantemente em paz entre elas, nós temos não uma teoria mas um suposto fato clamando por uma explicação, como os fatos fazem".

3. A não ser que se defenda o argumento de que guerras contra Estados democráticos seriam intrinsecamente mais longas e dispendiosas, daí uma natural inclinação à guerra contra Estados autoritários. Esse argumento não só não se sustenta, mas seria uma contradição direta com os pressupostos da teoria da paz democrática. Com efeito, teóricos que sustentam a tese diádica, de que democracias são mais pacíficas exclusivamente em seus relacionamentos entre si, devem se basear em um pressuposto moral, decerto compartilhado intersubjetivamente pelos cidadãos de uma dada democracia, de que lutar com outra democracia é naturalmente errado e condenável. 


\section{Clausewitz, o Realismo Estrutural e a Paz Democrática: Uma Abordagem Crítica}

4. $\mathrm{O}$ argumento institucionalista neoliberal clássico a respeito do papel das instituições internacionais na geração de cooperação interestatal pode ser encontrado em Keohane (1984), Martin (1992) e Keohane e Martin (1995).

5. Esse ponto parece ter sido importado da literatura que trata das dinâmicas da dissuasão convencional. Para um apanhado geral, ver Huth (1999) e Rhodes (1999).

6. A operacionalização das variáveis "realistas" é menos importante para a crítica que este artigo buscará desenvolver, mas não é em si desprovida de problemas. Tenha-se em mente, por exemplo, o critério de contiguidade/separação para a variável "geografia". Estados separados por menos de 240 km (150 milhas) de água são considerados contíguos, como se dividissem fronteira terrestre. Apenas o exemplo do Canal da Mancha, que separa a Inglaterra da Europa continental e apresenta apenas $33 \mathrm{~km}$ de largura em sua parte mais estreita, no estreito de Dover, serve para mostrar o quão irrealista é esse pressuposto. Toda a história da política internacional inglesa, particularmente em suas relações com os demais Estados europeus, foi direta e profundamente determinada pela separação entre o país e o continente pelo canal que os divide. Para a elaboração histórica desse ponto, ver Mearsheimer (2001, p. 261-264).

7. Para se ter uma noção do debate metodológico em torno da operacionalização e do teste das variáveis envolvidas no estudo da paz democrática, ver Chan (1984) e Bernoit (1996).

8. Da maneira como Oneal e Russett conduziram os testes, os aumentos e decréscimos controlados foram feitos em relação aos valores do Estado menos democrático em cada par, considerado o ator-chave para o teste da hipótese da paz democrática.

9. A respeito de Jomini, contemporâneo de Clausewitz e seu principal rival intelectual, pertencente ainda à tradição prescritiva de princípios e regras para o sucesso na guerra, ver Brinton et al. (1943), Shy (1986) e Proença Jr. et al. (1998). A respeito de outros autores importantes, antes e depois de Clausewitz, que também se propuseram a identificar princípios e regras para a vitória na guerra, ver Earle (1943) e Paret (1986).

10. Empregou-se o termo "oponente" no lugar de "inimigo" (enemy), utilizado por Paret e Howard em sua tradução para o inglês do livro Da guerra (On war) (CLAUSEWITZ, 1993), da qual serão extraídos e traduzidos os trechos citados neste artigo. Acredito que o termo "inimigo" é inadequado e a razão para esse julgamento é a distinção feita por Clausewitz entre intenção hostil e sentimento hostil. Enquanto a intenção hostil está necessariamente ligada à guerra, implícita no emprego da força contra o outro, o sentimento hostil não 


\section{Flávio Pedroso Mendes}

pertence intrinsecamente ao fenômeno, podendo ou não estar presente em casos particulares. Por essa razão, optou-se pela neutralidade do termo "oponente", que traduz unicamente a ideia de oposição. Essa observação vale para todo o texto.

11. $O$ entendimento que se segue a respeito da resposta final de Clausewitz para a anomalia das guerras reais, que caracteriza o estágio mais maduro de seu pensamento, é devido à pesquisa seminal de Diniz (2002).

12. The Attack, em Clausewitz (1993).

13. Para o argumento de que a abordagem estrutural do realismo se origina na realidade em Hobbes, ver Doyle (1997).

14. Nos próprios termos sugeridos por Waltz (1959), a teorização da política internacional exigia uma abordagem de terceira imagem ou sistêmica. Abordagens de primeira imagem têm como elemento analítico elementar atributos individuais ou humanos, como, por exemplo, a suposição de uma "natureza humana" (MORGENTHAU, 1993) e a consideração de atributos como liderança e habilidades do governante (que caracterizam, entre outras, a perspectiva realista de Maquiavel). Abordagens de segunda imagem privilegiam aspectos de Estado ou nação, como a forma de organização econômica e a natureza das instituições políticas.

15. Para uma boa discussão sobre como diferentes distribuições de papéis e funções podem levar a efeitos estruturais distintos, ver a comparação de Waltz (1979, cap. 5) entre o parlamentarismo britânico e o presidencialismo norte-americano.

16. O termo "seguramente" foi incluído porque, em tese, Estados podem vir ao socorro de outros quando os últimos estiverem em perigo; contudo, trata-se de uma situação incerta, em que os Estados tendem a não se pautar caso possam dispor de meios próprios para garantir a sua defesa.

17. A autoajuda é, aliás, uma tônica de qualquer ambiente anárquico como o sistema internacional, porém é substancialmente intensificada no último, em que guerras e destruição são possibilidades sempre presentes e terrivelmente recorrentes.

18. Entendam-se tática e estratégia nos termos da teoria da guerra de Clausewitz, como discutido na seção anterior. Para compreender por que a ambiguidade dos meios de força deve ser apreendida a partir de ambas as dimensões (tática e estratégia), ver Diniz (2002).

19. A lógica é simples: se há apenas duas grandes potências, há apenas um foco possível de conflito entre grandes potências no sistema, ao passo que em 


\section{Clausewitz, o Realismo Estrutural e a Paz Democrática: Uma Abordagem Crítica}

um sistema habitado por, por exemplo, três grandes potências (o menor sistema multipolar possível), são três os possíveis focos de conflito entre grandes potências. Considerando guerras entre uma grande potência e um Estado menor, a lógica é semelhante: em um mundo com, por exemplo, cem Estados menores, o sistema bipolar ofereceria duzentos possíveis focos de crise e instabilidade entre uma grande potência e um Estado menor; o sistema multipolar com três grandes potências, de sua parte, ofereceria trezentos possíveis focos de conflitos da mesma natureza. A propensão à estabilidade pesa ainda mais para o lado de um sistema bipolar se se considera a tendência à formação de alianças rígidas em torno das duas grandes potências do sistema. Assim, as grandes potências desincentivam confrontações dentro de seus próprios blocos, para não enfraquecê-los, e entre membros de seu bloco e o bloco antagônico, por temor de uma escalada. Em sistemas multipolares não só tendem a ser mais instáveis as alianças entre as grandes potências, mas também os Estados menores em geral não são pressionados a se aliar rigidamente com elas. Essa flexibilidade abre maiores possibilidades de conflito tanto entre grandes potências quanto entre grandes potências e Estados menores ou somente entre Estados menores. Ver Mearsheimer (1990).

20. Desequilíbrios de poder são mais comuns em um sistema multipolar, em primeiro lugar por uma questão de probabilidade: quanto maior o número de grandes potências, maiores as chances de que a distribuição de poder entre elas seja menos equânime. Ver Mearsheimer (2001). Em segundo lugar, agregue-se o fato de que em sistemas bipolares esforços internos de balanceamento (aprimoramento de suas próprias capacidades) são mais importantes do que os externos (formação de alianças), na medida em que não existem outras grandes potências no sistema; em sistemas multipolares, esforços externos predominam sobre os internos. O fato é que esforços internos tendem a ser muito mais eficientes do que esforços externos, os quais mantêm constantes os níveis internacionais de poder. Ver Waltz (1979).

21. Erros de cálculo se referem tanto às intenções quanto às capacidades de eventuais oponentes. Sistemas multipolares apresentam um maior número de potenciais rivais, aumentando o grau de incerteza quanto às suas intenções. Já em sistemas bipolares, uma grande potência tem apenas um principal rival: a outra. Isso diminui as incertezas e facilita o estabelecimento de regras tácitas de convivência entre elas. A possibilidade também colocada por sistemas multipolares de que coalizões sejam formadas entre grandes potências, na medida em que existem, por definição, três ou mais, aumenta os riscos de que Estados avaliem incorretamente a correlação de forças em uma eventual confrontação, subestimando o número de aliados em uma coalizão oponente ou superestimando o número em sua própria coalizão. Ver Mearsheimer (1990). 
22. A justificativa para a utilização do termo "esquisita" na tradução para o português, tendo sido traduzido para o inglês como paradoxical ("paradoxal") por Paret e Howard, encontra-se em Diniz (2002).

23. Beneficiou-se aqui da tradução para o português feita em Proença Jr. e Di$\operatorname{niz}(2006$, p. 27).

24. Isso muda em Mearsheimer (2001) e é uma de suas principais contribuições ao programa de pesquisa científico neorrealista.

25. A Guerra Fria também engloba, por exemplo, todo o período considerado por Bernoit (1996) em seu estudo similar.

\section{Referências Bibliográficas}

BERNOIT, Kenneth. Democracies really are more pacific (in general): reexamining regime type and war involvement. Journal of Conflict Resolution, v. 40, n. 4, p. 636-657, 1996.

BRINTON, Crane; CRAIG, Gordon A.; GILBERT, Felix. Jomini. In: EARLE, E. M. (Ed.). Makers of modern strategy: military thought from Machiavelli to Hitler. Princeton: Princeton University Press, 1943. p. 77-92.

CHAN, Steve. Mirror, mirror on the wall... Are the freer countries more pacific? Journal of Conflict Resolution, v. 28, n. 4, p. 617-648, 1984.

CLAUSEWITZ, Carl von. On war. Nova Iorque: Alfred A. Knopf, 1993.

DINIZ, Eugenio. Clausewitz, o balanço ataque-defesa e a teoria das relações internacionais. Tese (Doutorado em Engenharia de Produção) - Universidade Federal do Rio de Janeiro, Rio de Janeiro, 2002.

DOYLE, Michael. Ways of war and peace. Nova Iorque: W. W. Norton, 1997.

EARLE, Edward M. (Ed.). Makers of modern strategy: military thought from Machiavelli to Hitler. Princeton: Princeton University Press, 1943. 


\section{Clausewitz, o Realismo Estrutural e a Paz Democrática: Uma Abordagem Crítica}

GRAY, Colin. Clausewitz rules, OK? The future of the past - with GPS. In: COX, M.; BOOTH, K.; DUNNE, T. Interregnum: controversies in world politics, 1989-1999. Cambridge: Cambridge University Press, 1999. p. 161-182.

HERZ, John H. Idealist internationalism and the security dilemma. World Politics, v. 2, n. 2, p. 157-180, 1950.

HUTH, Paul K. Deterrence and international conflict: empirical findings and theoretical debate. Annual Review of Political Science, v. 2, p. 25-48, 1999.

KEOHANE, Robert O. After hegemony: cooperation and discord in the world political economy. Princeton: Princeton University Press, 1984.

; MARTIN, Lisa. The promise of institutionalist theory. International Security, v. 20, n. 1, p. 39-51, 1995.

MARTIN, Lisa. Institutions and cooperation: sanctions during the Falkland Islands conflict. International Security, v. 16, n. 4, p. 143-178, 1992.

MEARSHEIMER, John J. Back to the future. International Security, v. 15, n. 1, p. 3-54, 1990. 2001.

The tragedy of great powers politics. 1. ed. Nova Iorque: W. W. Norton,

MORGENTHAU, Hans J. Politics among nations: the struggle for power and peace. Nova Iorque: McGraw Hill, 1993.

ONEAL, John; RUSSETT, Bruce. Triangulating peace - democracy, interdependence and international organizations. Nova Iorque: W.W. Norton, 2001.

PARET, Peter (Ed.). Makers of modern strategy: from Machiavelli to the nuclear age. 1. ed. Princeton: Princeton University Press, 1986.

PROENÇA JR., Domício; DINIZ, Eugenio. O fenômeno guerra. Rio de Janeiro: Grupo de Estudos Estratégicos, COPPE-UFRJ, 2006. [Manuscrito inédito].

; RAZA, Salvador Ghelfi. Guia de estudos de estratégia. Rio de Janeiro: Jorge Zahar, 1998.

RHODES, Edward. Review of Empirical Studies of Conventional Deterrence. Nova Iorque: Columbia International Affairs Online/Columbia University Press, 1999. [Working paper]. 
SHY, John. Jomini. In: PARET, P. (Ed.). Makers of modern strategy: from Machiavelli to the nuclear age. 1. ed. Princeton: Princeton University Press, 1986. p. 143-185.

WALTZ, Kenneth N. Man, the State and war. Nova Iorque: Columbia University Press, 1959.

Theory of international politics. Nova Iorque: McGraw-Hill, 1979.

Structural realism after the Cold War. International Security, v. 25, n. 1, p. 5-42, 2000.

\section{Resumo}

\section{Clausewitz, o Realismo Estrutural e a Paz Democrática: Uma Abordagem Crítica}

Propõe-se a apreciação crítica do sistemático estudo da paz democrática realizado por Oneal e Russett em Triangulating peace - democracy, interdependence and international organizations (2001). O estudo de Oneal e Russett é importante e representativo porque oferece uma construção teórica para explicar um suposto "fato" internacional e porque tenta incorporar e controlar algumas variáveis identificadas com a principal abordagem rival: o realismo político. Argumentar-se-á que Oneal e Russett falham em suas duas principais tentativas de contribuição. O princípio causal identificado pelos autores não resiste ao entendimento, derivado da teoria da guerra de Clausewitz, da guerra como um fenômeno integralmente político. Incidentalmente, essa crítica também será válida para o empreendimento dos teóricos da paz democrática como um todo, na medida em que compartilhem os mesmos pressupostos. E os autores não são capazes de identificar e controlar as variáveis "realistas" como pretendido, não se precavendo, portanto, contra a crítica de epifenomenalidade.

Palavras-chave: Paz Democrática - Clausewitz - Teoria da Guerra - Realismo Estrutural 


\section{Clausewitz, o Realismo Estrutural e a Paz Democrática: Uma Abordagem Crítica}

\section{Abstract}

\section{Clausewitz, Structural Realism and the Democratic Peace: A Critical Approach}

The purpose of the article is to undertake a critical analysis of the democratic peace approach laid out in Oneal and Russett's Triangulating peace - democracy, interdependence and international organizations (2001). This study offers a theoretical framework to explain a supposed international "fact" and attempts to incorporate and control some variables of the main approach it seeks to challenge - structural realism. The article argues that Oneal and Russett fail in their two main attempted contributions. The causal mechanism identified by the authors does not withstand resist the understanding, derived from Clausewitz's theory of war, of war as an integral political phenomenon. Incidentally, this criticism also applies to other prominent works on the democratic peace, given these share the same assumptions. Furthermore, the authors are incapable of identifying and controlling the "realist" variables as planned, which makes them vulnerable to the criticism of epiphenomenalism.

Keywords: Democratic Peace - Clausewitz - Theory of War - Structural Realism 